\title{
Stereo- and Regiocontrolled Methylboration of Terminal Alkynes
}

\author{
Oleksandr Zhurakovskyi, ${ }^{\circledR}$ Rafael M. P. Dias, ${ }^{\circledR}$ Adam Noble, ${ }^{\circledR}$ and Varinder K. Aggarwal*º
}

School of Chemistry, University of Bristol, Cantock's Close, Bristol BS8 1TS, U.K.

Supporting Information

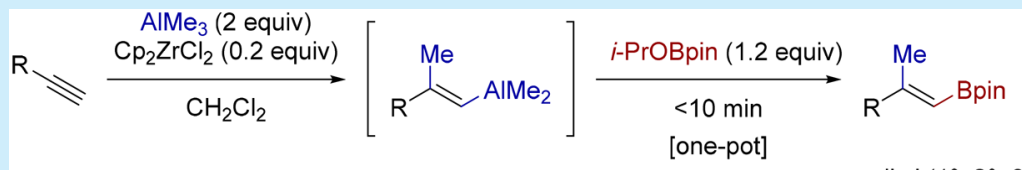

$$
\begin{aligned}
& R=\operatorname{alkyl}\left(1^{\circ}, 2^{\circ}, 3^{\circ}\right)
\end{aligned}
$$

ABSTRACT: A scalable and operationally simple synthesis of trisubstituted alkenyl boronic esters has been achieved using a $\mathrm{Zr}$ catalyzed carboalumination of terminal alkynes followed by in situ transmetalation with $i$-PrOBpin. The products are formed in good yields and with excellent regioselectivity and perfect stereoselectivity. The new procedure provides a significant improvement over the previously reported syntheses.

$\mathrm{T}$ erminal trisubstituted alkenyl boronates are highly important substrates in synthetic chemistry, with application in a variety of useful transformations, including the Suzuki-Miyaura cross coupling, ${ }^{1 \mathrm{a}, \mathrm{b}}$ radical additions, ${ }^{1 \mathrm{c}-\mathrm{e}}$ and transition-metal-free cross couplings. ${ }^{1 \mathrm{f,g}}$ The required boronate esters can be accessed from various precursors, including alkynes, ${ }^{2 \mathrm{a}-\mathrm{c}}$ alkenes, ${ }^{2 \mathrm{~d}-\mathrm{g}}$ epoxides, ${ }^{2 \mathrm{~h}}$ allenes, ${ }^{2 \mathrm{i}} \mathrm{ke}-$ tones, and aldehydes. ${ }^{2 j, k}$ The carboboration of terminal alkynes represents a particularly attractive method to access alkenyl boronates due to the concomitant introduction of both alkyl and boron groups. Historically, this transformation has been achieved by initial carboalumination, ${ }^{3}$ followed by iodination, isolation, and finally, borylation ${ }^{4,5}$ (Figure 1A). More direct

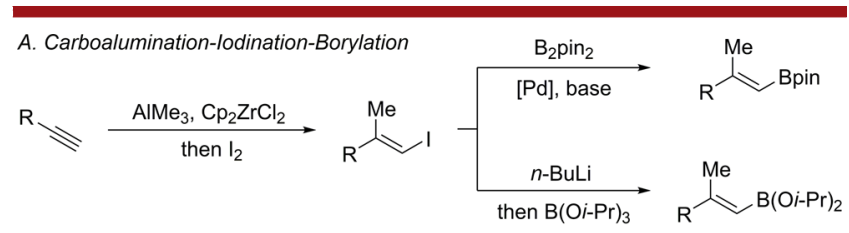

B. Cu-Catalyzed Carboborations

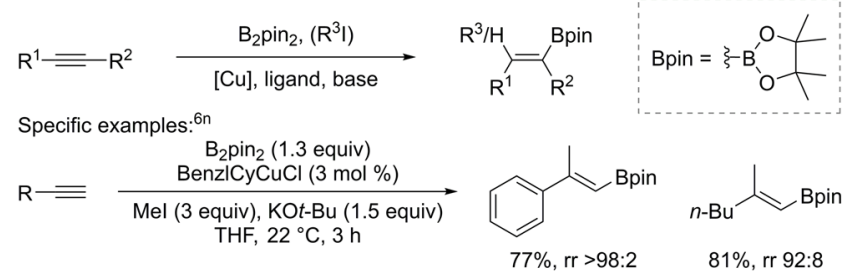

C. This Work: Zr-Catalyzed Carboalumination-Transmetalation

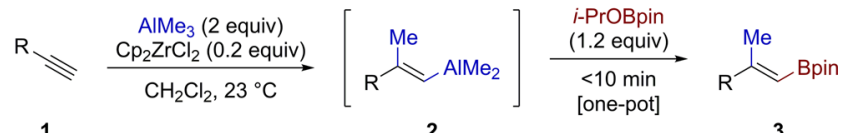

$$
\begin{aligned}
& 1 \quad \mathrm{R}=\operatorname{alkyl}\left(1^{\circ}, 2^{\circ}, 3^{\circ}\right) \text {, vinyl, aryl }
\end{aligned}
$$

Figure 1. Synthesis of alkenyl boronates from alkynes. methods are desirable and have been reported. One-step carboborations of terminal or internal alkynes are possible under transition-metal catalysis with $\mathrm{B}_{2} \mathrm{pin}_{2}$ as the boron source (Figure $1 \mathrm{~B}){ }^{2 \mathrm{a}-c, 6}$ However, while high regioselectivity can be obtained with aryl-substituted alkynes, product ratios are invariably lower with alkyl-substituted terminal alkynes. ${ }^{7-9}$

We considered the possibility of using intermediate alkenyl alanes, generated from the well-established carboalumination of alkynes, $^{3 a-c}$ in a transmetalation process with trialkoxyboronates. Such transmetalation processes $(\mathrm{Al} \rightarrow \mathrm{B})$ are rare. In fact, based on typical bond strengths, the transmetalation process is expected to be strongly endothermic by $101 \mathrm{~kJ} / \mathrm{mol}$ due primarily to the high $\mathrm{B}-\mathrm{O}$ bond strength and so should not proceed. ${ }^{10,11}$ However, a limited precedent does exist. Hoveyda showed that trialkoxyboronates could transmetalate alkenyl alanes generated by a Ni-catalyzed addition of DIBAL-H to terminal alkynes, ${ }^{12}$ and Thomas and Cowley reported that pinacol borane was able to transmetalate alkenyl alanes generated by a DIBAL-H addition to terminal alkynes. ${ }^{13}$

Herein, we report the successful development of this reaction, which provides an operationally simple protocol to convert terminal alkynes $\mathbf{1}$ into trisubstituted alkenyl boronates 3 in one pot using readily available chemicals. The carboborations proceed with high regio- and stereoselectivities and with improved yields when compared to previous approaches (Figure 1C).

To test the feasibility of the $\mathrm{Al} \rightarrow \mathrm{B}$ transmetalation, we prepared alkenyl alane $2 \mathrm{a}$ by a $\mathrm{Cp}_{2} \mathrm{ZrCl}_{2}$-catalyzed Negishi carboalumination of 1 -octyne (1a) with $\mathrm{AlMe}_{3}$ (Table 1). In the same pot, treatment of alkenyl alane $2 \mathrm{a}$ with $i$-PrOBpin, a cheap and widely available reagent, resulted in an extremely fast formation of the desired alkenyl boronate $\mathbf{3 a}$ in high yield and with excellent regioselectivity ( $r r$ 98:2). It was found that only 1.2 equiv of $i$-PrOBpin was required for complete borylation in

Received: April 19, 2018

Published: May 9, 2018 


\section{Table 1. Reaction Optimization}

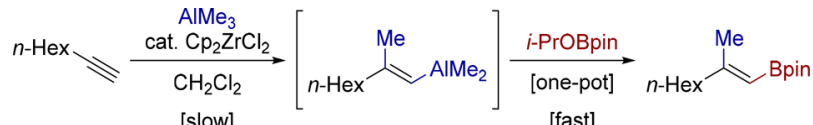

$$
\begin{aligned}
& \text { 1a } \quad \text { 2a } \quad \text { slow] } \\
& \begin{array}{ccc}
\text { entry } & \multicolumn{1}{c}{\text { conditions }^{a}} & \multicolumn{1}{c}{\text { result }} \\
1 & 2 \text { equiv of } \mathrm{AlMe}_{3}, 0.2 \text { equiv of } \mathrm{Cp}_{2} \mathrm{ZrCl}_{2}, \\
& \begin{array}{l}
\text { reagent-grade } \mathrm{CH}_{2} \mathrm{Cl}_{2}, 23{ }^{\circ} \mathrm{C}, 9 \mathrm{~h} \text {; then } 1.2 \\
\text { equiv of } i \text {-PrOBpin, } 0-23{ }^{\circ} \mathrm{C}, 10 \mathrm{~min}
\end{array} & 82 \% \text { yield, }{ }^{b} \mathrm{rr} 98: 2^{c}
\end{array} \\
& \text { deviations from the above } \\
& 2 \text { anhydrous } \mathrm{CH}_{2} \mathrm{Cl}_{2} \text { used incomplete [Al] } \\
& 3 \text { addition of } 1 \text { equiv of } \mathrm{H}_{2} \mathrm{O} \text { during } \quad \text { 70\% yield, rr } 97: 3 \\
& \text { carboalumination; } 2 \text { equiv of } i \text {-PrOBpin } \quad 53 \% \text { yield, } \\
& \text { rr >99:1 } \\
& \text { rr }>98: 2 \\
& 5 \quad i \text {-PrOBpin added at } 23{ }^{\circ} \mathrm{C}
\end{aligned}
$$

${ }^{a}$ Reactions performed with $0.45 \mathrm{mmol}$ of 1a. ${ }^{b}$ Isolated yield. ${ }^{c}$ Measured by ${ }^{1} \mathrm{H}$ NMR analysis of the crude reaction mixtures.

less than $10 \mathrm{~min}$. The reaction did not require anhydrous solvents (entry 2 vs 1 ), and in fact, the carboalumination step was slightly faster in reagent-grade $\mathrm{CH}_{2} \mathrm{Cl}_{2}(\sim 500 \mathrm{ppm}$ of
$\mathrm{H}_{2} \mathrm{O}$ ). Deliberate addition of 1 equiv of water to the reaction mixture (entry 3$)^{3 \mathrm{~h}, \mathrm{i}}$ resulted in an exceedingly fast carboalumination $(<10 \mathrm{~min})$. However, the yield of alkenyl boronate $3 \mathrm{a}$ dropped to $53 \%$. The use of excess reagents (entry 4) did not alter the yield or regioselectivity but did accelerate the carboalumination step. The $\mathrm{Al} \rightarrow \mathrm{B}$ exchange was extremely fast, and a temperature increase was observed upon the addition of $i$-PrOBpin to the alkenyl alane. This heat evolution initially led to reduced yields $(35-45 \%)$ when the reactions were scaled up or performed on sensitive substrates (vide infra), with products of protodemetalation accounting for the remaining mass balance (entry 5). Thus, small-scale $\mathrm{Al} \rightarrow \mathrm{B}$ exchange was performed by adding the $i$-PrOBpin at $0{ }^{\circ} \mathrm{C}$ before allowing the reaction mixture to warm to room temperature. Since the reaction was expected to be endothermic based on bond strengths, the surprising exotherm observed must be caused by other processes, such as the formation of dimers or other oligomeric structures of the $i$ $\mathrm{PrOAlMe}_{2}$ byproduct. $^{14}$

We then applied the optimized carboboration conditions to a range of alkynes to test its scope (Scheme 1). Nineteen alkynes were reacted on a $0.5 \mathrm{mmol}$ scale to give the alkenyl boronate products in generally high yields (ca. 80\%) and with excellent regioselectivities (up to $>98: 2 \mathrm{rr}$ ). In many cases, the isolated yields and/or regioisomeric ratios were significantly higher than those previously reported. For example, trifluoromethylated

Scheme 1. One-Pot Synthesis of Alkenyl Boronates $3 a-q$

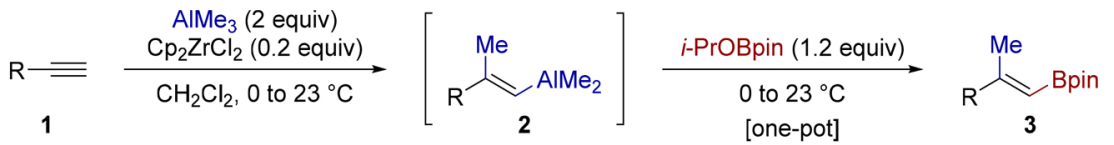
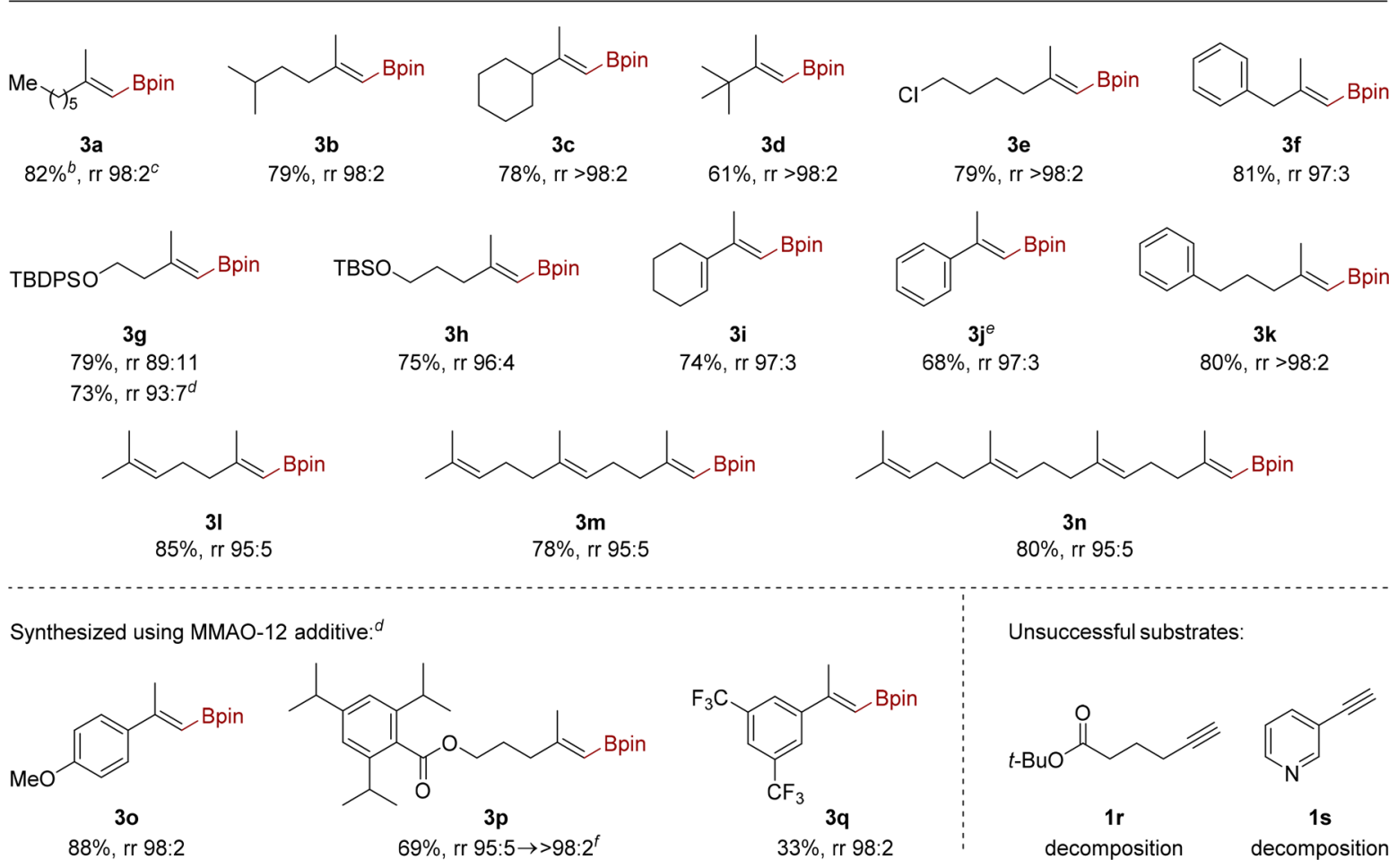

${ }^{a}$ Reaction conditions: $1(0.5 \mathrm{mmol}), 2$ equiv of $\mathrm{AlMe}_{3}, 0.2$ equiv of $\mathrm{Cp}_{2} \mathrm{ZrCl}_{2}$, reagent-grade $\mathrm{CH}_{2} \mathrm{Cl}_{2}, 0-23{ }^{\circ} \mathrm{C}$, $14 \mathrm{~h}$; then 1.2 equiv of $i$-PrOBpin, $0-23{ }^{\circ} \mathrm{C}, 60 \mathrm{~min} .{ }^{b}$ Yields are given for isolated products after $\mathrm{SiO}_{2}$ column chromatography. ${ }^{c}$ Regioisomeric ratios are given for crude reaction mixtures and measured by ${ }^{1} \mathrm{H}$ NMR spectroscopy. ${ }^{d}$ Carboalumination performed in the presence of 1 equiv of modified methylaluminoxane (MMAO-12). ${ }^{e}$ Carboalumination performed for 96 h. ${ }^{f}$ Regioisomeric ratio after column chromatography. 
boronate $3 q$ could not be prepared using the previously reported copper-catalyzed carboboration. ${ }^{6 a}$ However, using our method, 3q was formed in a synthetically viable $33 \%$ yield and with excellent regioselectivity.

Alkynes bonded to primary (1b), secondary (1c), and even tertiary carbon centers (1d) reacted equally well (the slightly reduced yield of $3 \mathbf{d}$ can be explained by the volatility of the starting material, bp $37-38{ }^{\circ} \mathrm{C}^{15}$ ), thus demonstrating that the reaction tolerates the full spectrum of steric demand. Conjugation of the alkyne to an alkene or an aromatic ring slowed the carboalumination step (1i: $20 \mathrm{~h} ; \mathbf{1 j}$ : $96 \mathrm{~h}$ ), but the overall yield and regioselectivity remained high. Silyl ethers (1g, 1h) and alkyl chlorides (3e) were well tolerated, although slightly reduced regioselectivity (rr 89:11) was observed for the two-carbon-tethered silyl ether $3 \mathrm{~g}$, presumably arising from the $\mathrm{O} \rightarrow \mathrm{Al}$ coordination.

The success of the overall transformation depended on the ability to perform the initial carboalumination and thus followed the general trends known for this reaction. ${ }^{3 \mathrm{~b}, \mathrm{c}}$ In particular, the presence of sterically accessible Lewis basic sites interfered with this step $(\mathbf{1 0}-\mathbf{s})$. For example, almost no reaction was observed for ester $1 \mathbf{p}$, even when 4 equiv of $\mathrm{AlMe}_{3}$ were used or when the reaction mixture was heated at $60^{\circ} \mathrm{C}$ in 1,2-dichloroethane. Pleasingly, the reactivity of this substrate, and others bearing Lewis basic functional groups, could be dramatically improved by the addition of modified methylaluminoxane (MMAO-12, 1 equiv). ${ }^{16}$ Thus, the ester $3 p$ was obtained in 69\% yield ( $\mathrm{rr}$ 95:5, improved to $>98: 2$ by chromatography). Silyl ether $\mathbf{3 g}$ was formed with $\operatorname{rr}$ 93:7, compared with $89: 11$ for the additive-free reaction. On the other hand, 3-pyridyl alkyne 1s yielded no desired boronate, even in the presence of MMAO-12, with products of ring methylation observable by GCMS and NMR.

The utility of the carboalumination-borylation sequence was further demonstrated by performing gram-scale reactions (Scheme 2). We targeted four substrates, for which direct comparisons with the literature protocols could be made. ${ }^{6 n, 17-19}$ Carboalumination was smoothly performed on a $6 \mathrm{mmol}$ scale, the slight exotherm being controlled by

Scheme 2. Gram-Scale Synthesis of Alkenyl Boronates

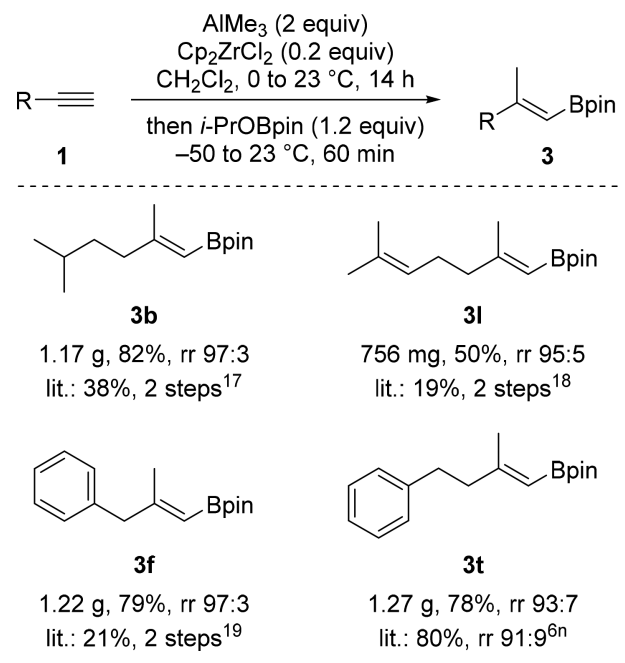

${ }^{a}$ Reagents and conditions: 1 ( $\left.6 \mathrm{mmol}\right), 2$ equiv of $\mathrm{AlMe}_{3}, 0.2$ equiv of $\mathrm{Cp}_{2} \mathrm{ZrCl}_{2}, \mathrm{CH}_{2} \mathrm{Cl}_{2}, 0-23{ }^{\circ} \mathrm{C}, 14 \mathrm{~h}$; then 1.2 equiv of $i$-PrOBpin, -50 to $+23{ }^{\circ} \mathrm{C}, 1 \mathrm{~h}$. precooling the $\mathrm{AlMe}_{3} / \mathrm{Cp}_{2} \mathrm{ZrCl}_{2}$ mixture to $0{ }^{\circ} \mathrm{C}$. After $14 \mathrm{~h}$, $i$ PrOBpin was added in one portion at $-50{ }^{\circ} \mathrm{C}$, and the mixture was allowed to warm to $23{ }^{\circ} \mathrm{C}$. The cryogenic cooling was essential in order to obtain good yields on gram scale. When we attempted to control the exotherm by slow addition of $i$ PrOBpin at $0{ }^{\circ} \mathrm{C}$, alkenyl boronate $3 \mathbf{b}$ was obtained in only $50 \%$ yield. Only when the borylating agent was added in one portion could $82 \%$ of the product be obtained. ${ }^{20}$ Under these conditions, compound $\mathbf{3 b}$ was isolated in $82 \%$ yield, ${ }^{17}$ 3f in $79 \%$ yield, ${ }^{19} 3 \mathbf{t}$ in $78 \%$, but with improved regioselectivity, ${ }^{6}$ and isoprenylated boronate 31 in $50 \%$ yield. ${ }^{18}$ In almost all cases, significant improvements over the literature procedures were achieved.

In summary, we have developed a straightforward synthesis of terminal trisubstituted alkenyl boronates from nonactivated terminal alkynes. The reaction uses cheap and easily available commercial materials, does not require flame-dried glassware, and is scalable to gram amounts. The reaction is applicable to a broad range of alkyne substrates, and the products are formed with good-to-excellent regioselectivities.

\section{ASSOCIATED CONTENT}

\section{Supporting Information}

The Supporting Information is available free of charge on the ACS Publications website at DOI: 10.1021/acs.orglett.8b01252.

General reaction procedures, characterization data, and NMR spectra for alkenyl boronates 3 (PDF)

\section{AUTHOR INFORMATION}

\section{Corresponding Author}

*E-mail: v.aggarwal@bristol.ac.uk.

ORCID (-)

Oleksandr Zhurakovskyi: 0000-0002-2096-2202

Rafael M. P. Dias: 0000-0002-0780-8382

Adam Noble: 0000-0001-9203-7828

Varinder K. Aggarwal: 0000-0003-0344-6430

Notes

The authors declare no competing financial interest.

\section{ACKNOWLEDGMENTS}

We thank the EPSRC (EP/I038071/1), the H2020 ERC (670668), and the University of Bristol for financial support. R.M.P.D. is grateful to the CAPES Foundation for a fellowship (Grant No. 88881.120469/2016-01).

\section{REFERENCES}

(1) Suzuki-Miyaura cross coupling: (a) Miyaura, N.; Suzuki, A. Chem. Rev. 1995, 95, 2457-2483. (b) Kotha, S.; Lahiri, K.; Kashinath, D. Tetrahedron 2002, 58, 9633-9695. Radical additions: (c) Noble, A.; Mega, R. S.; Pflästerer, D.; Myers, E. L.; Aggarwal, V. K. Angew. Chem., Int. Ed. 2018, 57, 2155-2159. (d) Silvi, M.; Sandford, C.; Aggarwal, V. K. J. Am. Chem. Soc. 2017, 139, 5736-5739. (e) Guennouni, N.; Lhermitte, F.; Cochard, S.; Carboni, B. Tetrahedron 1995, 51, 6999-7018. Transition-metal-free cross couplings: (f) Armstrong, R. J.; Sandford, C.; García-Ruiz, C.; Aggarwal, V. K. Chem. Commun. 2017, 53, 4922-4925. (g) Armstrong, R. J.; Aggarwal, V. K. Synthesis 2017, 49, 3323-3336.

(2) Synthesis of boronate esters from alkynes: (a) Yoshida, H. ACS Catal. 2016, 6, 1799-1811. (b) Barbeyron, R.; Benedetti, E.; Cossy, J.; Vasseur, J. J.; Arseniyadis, S.; Smietana, M. Tetrahedron 2014, 70, 
8431-8452. (c) Yun, J. Asian J. Org. Chem. 2013, 2, 1016-1025. From alkenes: (d) Takahashi, K.; Takagi, J.; Ishiyama, T.; Miyaura, N. Chem. Lett. 2000, 29, 126-127. (e) Kiesewetter, E. T.; O’Brien, R. V.; Yu, E. C.; Meek, S. J.; Schrock, R. R.; Hoveyda, A. H. J. Am. Chem. Soc. 2013, 135, 6026-6029. (f) Morrill, C.; Grubbs, R. H. J. Org. Chem. 2003, 68, 6031-6034. (g) Kirai, N.; Iguchi, S.; Ito, T.; Takaya, J.; Iwasawa, N. Bull. Chem. Soc. Jpn. 2013, 86, 784-799. From epoxides: (h) Murray, S. A.; Luc, E. C. M.; Meek, S. J. Org. Lett. 2018, 20, 469472. From allenes: (i) Meng, F.; Jung, B.; Haeffner, F.; Hoveyda, A. H. Org. Lett. 2013, 15, 1414-1417. From ketones and aldehydes: (j) Stephens, T. C.; Pattison, G. Org. Lett. 2017, 19, 3498-3501. (k) Matteson, D. S.; Moody, R. J. Organometallics 1982, 1, 20-28.

(3) Carboalumination reviews: (a) Negishi, E. I. ARKIVOC 2011, 34-53. (b) Normant, J. F.; Alexakis, A. Synthesis 1981, 1981, 841870. (c) Negishi, E.; Kondakov, D. Y. Chem. Soc. Rev. 1996, 25, 417. Seminal publications: (d) Van Horn, D. E.; Negishi, E. J. Am. Chem. Soc. 1978, 100, 2252-2254. (e) Negishi, E.; Okukado, N.; King, A. O.; Van Horn, D. E.; Spiegel, B. I. J. Am. Chem. Soc. 1978, 100, 22542256. (f) Negishi, E.; Van Horn, D. E.; Yoshida, T. J. Am. Chem. Soc. 1985, 107, 6639-6647. Mechanistic studies: (g) Yoshida, T.; Negishi, E. J. Am. Chem. Soc. 1981, 103, 4985-4987. Water-promoted carboaluminations: (h) Wipf, P.; Lim, S. Angew. Chem., Int. Ed. Engl. 1993, 32, 1068-1071. (i) Wipf, P.; Nunes, R. L.; Ribe, S. Helv. Chim. Acta 2002, 85, 3478-3488.

(4) Miyaura borylation: (a) Ishiyama, T.; Murata, M.; Miyaura, N. J. Org. Chem. 1995, 60, 7508-7510. Review: (b) Kubota, K.; Iwamoto, H.; Ito, H. Org. Biomol. Chem. 2017, 15, 285-300.

(5) (a) Organ, M. G.; Bilokin, Y. V.; Bratovanov, S. J. Org. Chem. 2002, 67, 5176-5183. (b) Li, W.; Nelson, D. P.; Jensen, M. S.; Hoerrner, R. S.; Cai, D.; Larsen, R. D.; Reider, P. J. J. Org. Chem. 2002, 67, 5394-5397.

(6) Cu-catalyzed carboboration: (a) Alfaro, R.; Parra, A.; Alemán, J.; García Ruano, J. L.; Tortosa, M. J. Am. Chem. Soc. 2012, 134, 1516515168. (b) Liu, P.; Fukui, Y.; Tian, P.; He, Z.-T.; Sun, C.-Y.; Wu, N.Y.; Lin, G.-Q. J. Am. Chem. Soc. 2013, 135, 11700-11703. (c) Yoshida, H.; Kageyuki, I.; Takaki, K. Org. Lett. 2013, 15, 952-955. (d) Kageyuki, I.; Yoshida, H.; Takaki, K. Synthesis 2014, 46, 1924-1932. (e) Semba, K.; Bessho, N.; Fujihara, T.; Terao, J.; Tsuji, Y. Angew. Chem., Int. Ed. 2014, 53, 9007-9011. (f) Zhou, Y.; You, W.; Smith, K. B.; Brown, M. K. Angew. Chem., Int. Ed. 2014, 53, 3475-3479. (g) Bidal, Y. D.; Lazreg, F.; Cazin, C. S. J. ACS Catal. 2014, 4, 1564-1569. (h) Su, W.; Gong, T.-J.; Lu, X.; Xu, M.-Y.; Yu, C.-G.; Xu, Z.-Y.; Yu, H.-Z.; Xiao, B.; Fu, Y. Angew. Chem., Int. Ed. 2015, 54, 12957-12961. (i) Kubota, K.; Iwamoto, H.; Yamamoto, E.; Ito, H. Org. Lett. 2015, 17, 620-623. (j) Bin, H.-Y.; Wei, X.; Zi, J.; Zuo, Y.-J.; Wang, T.-C.; Zhong, C.-M. ACS Catal. 2015, 5, 6670-6679. (k) Itoh, T.; Shimizu, Y.; Kanai, M. J. Am. Chem. Soc. 2016, 138, 7528-7531. (1) Su, W.; Gong, T.-J.; Zhang, Q.; Zhang, Q.; Xiao, B.; Fu, Y. ACS Catal. 2016, 6, 6417-6421. (m) Kageyuki, I.; Osaka, I.; Takaki, K.; Yoshida, H. Org. Lett. 2017, 19, 830-833. (n) Mun, B.; Kim, S.; Yoon, H.; Kim, K. H.; Lee, Y. J. Org. Chem. 2017, 82, 6349-6357.

(7) Other methods include bromoboration of alkynes with $\mathrm{BBr}_{3}$ followed by esterification and Negishi coupling, ${ }^{8}$ and $\mathrm{Ni}-$ or Pdcatalyzed intramolecular boration of tethered alkynes. ${ }^{9}$

(8) (a) Wang, C.; Tobrman, T.; Xu, Z.; Negishi, E. Org. Lett. 2009, 11, 4092-4095. (b) Negishi, E. I.; Tobrman, T.; Rao, H.; Xu, S.; Lee, C. T. Isr. J. Chem. 2010, 50, 696-701.

(9) (a) Yamamoto, A.; Suginome, M. J. Am. Chem. Soc. 2005, 127, 15706-15707. (b) Suginome, M.; Yamamoto, A.; Murakami, M. J. Am. Chem. Soc. 2003, 125, 6358-6359. (c) Daini, M.; Yamamoto, A.; Suginome, M. J. Am. Chem. Soc. 2008, 130, 2918-2919.

(10) Using the standard bond energies, ${ }^{11}$ one can estimate the $\mathrm{Al} \rightarrow \mathrm{B}$ exchange to be endothermic with $\Delta H^{298}=+101 \mathrm{~kJ} / \mathrm{mol}$ :

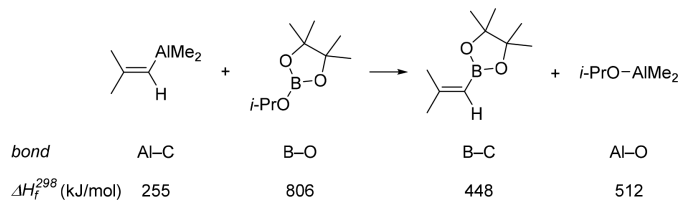

(11) (a) Dean, J. A., Ed. Bond Dissociation Energies. In Lange's Handbook of Chemistry, 15th ed; McGraw-Hill: New York, 1999; pp 329-330. (b) King, R. B., Crabtree, R. H., Lukehart, C. M., Atwood, D. A., Scott, R. A., Eds. Bond Energies. In Encyclopedia of Inorganic Chemistry; Wiley, 2006; DOI: 10.1002/0470862106.id098.

(12) Gao, F.; Hoveyda, A. H. J. Am. Chem. Soc. 2010, 132, 1096110963.

(13) Bismuto, A.; Thomas, S. P.; Cowley, M. J. Angew. Chem., Int. Ed. 2016, 55, 15356-15359.

(14) The additional $\mathrm{Al}-\mathrm{O}$ bonds formed in the dimerization of $i$ $\mathrm{PrOAlMe}_{2}$ may contribute to the exotherm observed. See: Allan, J. F.; Clegg, W.; Elsegood, M. R. J.; Henderson, K. W.; McKeown, A. E.; Moran, P. H.; Rakov, I. M. J. Organomet. Chem. 2000, 602, 15.

(15) Ďuriš, A.; Daïch, A.; Santos, C.; Fleury, L.; Ausseil, F.; Rodriguez, F.; Ballereau, S.; Génisson, Y.; Berkeš, D. Chem. - Eur. J. 2016, 22, 6676-6686.

(16) Kaminsky, W. Macromol. Chem. Phys. 1996, 197, 3907-3945.

(17) Hieda, Y.; Choshi, T.; Fujioka, H.; Hibino, S. Eur. J. Org. Chem. 2013, 2013, 7391-7401.

(18) Salvaggio, F.; Hodgkinson, J. T.; Carro, L.; Geddis, S. M.; Galloway, W. R. J. D.; Welch, M.; Spring, D. R. Eur. J. Org. Chem. 2016, 2016, 434-437.

(19) Chen, J. L. Y.; Aggarwal, V. K. Angew. Chem., Int. Ed. 2014, 53, $10992-10996$.

(20) It is possible that the excess alkenyl alane intermediate 2 reacts with the newly formed boronate 3 when $i$-PrOBpin is added slowly. Rapid addition of $i$-PrOBpin diminishes the extent of this side reaction at the cost of rapid heat evolution, which is controlled by precooling the reaction mixture to $-50{ }^{\circ} \mathrm{C}$. 